\title{
Temporal Dynamics of Chronic Inflammation on the Cecal Microbiota in IL-10 ${ }^{-/-}$Mice
}

\begin{abstract}
Anne-Marie C. Overstreet ${ }^{1}$, Amanda E. Ramer-Tait ${ }^{2}$, Jan S. Suchodolski ${ }^{3}$, Jesse M. Hostetter ${ }^{4}$, Chong Wang ${ }^{5}$, Albert E. Jergens ${ }^{6}$, Gregory J. Phillips ${ }^{1}$ and Michael J. Wannemuehler ${ }^{\text {* }}$

${ }^{1}$ Department of Veterinary Microbiology and Preventive Medicine, lowa State University, Ames, IA, United States, 2 Department of Food Science and Technology, University of Nebraska, Lincoln, NE, United States, ${ }^{3}$ GI Laboratory, Department of Small Animal Clinical Sciences, Texas A\&M University, College Station, TX, United States, ${ }^{4}$ Department of Pathology, University of Georgia, Athens, GA, United States, ${ }^{5}$ Veterinary Diagnostics and Production Animal Medicine, lowa State University, Ames, IA, United States, ${ }^{6}$ Veterinary Clinical Science, lowa State University, Ames, IA, United States
\end{abstract}

OPEN ACCESS

Edited by:

Christoph Mueller,

University of Bern, Switzerland

Reviewed by:

Christine Josenhans,

Ludwig Maximilian University of

Munich, Germany

Andre Bleich,

Hannover Medical School, Germany Marijana Basic,

Hannover Medical School, Germany,

in collaboration with reviewer $A B$

*Correspondence:

Michael J. Wannemuehler miwannem@iastate.edu

Specialty section:

This article was submitted to

Mucosal Immunity,

a section of the journal

Frontiers in Immunology

Received: 27 August 2020 Accepted: 21 December 2020 Published: 16 February 2021

Citation:

Overstreet A-MC, Ramer-Tait $A E$

Suchodolski JS, Hostetter JM Wang $C$, Jergens $A E$, Phillips GJ and Wannemuehler MJ (2021) Temporal Dynamics of Chronic Inflammation on the Cecal Microbiota in IL-10-- Mice.

Front. Immunol. 11:585431.

doi: 10.3389/fimmu.2020.585431
The intestinal microbiota is a critical component of mucosal health as evidenced by the fact that alterations in the taxonomic composition of the gastrointestinal microbiota are associated with inflammatory bowel diseases. To better understand how the progression of inflammation impacts the composition of the gastrointestinal microbiota, we used culture independent taxonomic profiling to identify temporal changes in the cecal microbiota of $\mathrm{C} 3 \mathrm{Bir} \mathrm{IL}-10^{-/-}$mice concomitantly with the onset and progression of colitis. This analysis revealed that $\mathrm{IL}-10^{-/-}$mice displayed a biphasic progression in disease severity, as evidenced by histopathological scores and cytokine production. Beginning at 4 weeks of age, pro-inflammatory cytokines including TNF- $\alpha$, IFN- $\gamma$, IL-6, GCSF, and IL- $1 \alpha$ as well as chemokines including RANTES and MIP-1 $\alpha$ were elevated in the serum of $\mathrm{IL}-10^{-/-}$mice. By 19 weeks of age, the mice developed clinical signs of disease as evidenced by weight loss, which was accompanied by a significant increase in serum levels of $\mathrm{KC}$ and IL-17. While the overall diversity of the microbiota of both wild type and $\mathrm{IL}-10^{-/-}$were similar in young mice, the latter failed to increase in complexity as the mice matured and experienced changes in abundance of specific bacterial taxa that are associated with inflammatory bowel disease in humans. Collectively, these results reveal that there is a critical time in young mice between four to six weeks of age when inflammation and the associated immune responses adversely affect maturation of the microbiota.

Keywords: IBD, IL-10, enterobacteriaceae, colitis, microbiome, temporal dynamic changes, dysbiosis, cytokine response

\section{INTRODUCTION}

Inflammatory bowel diseases (IBD), which include Crohn's disease (CD) and ulcerative colitis (UC), are chronic immunologically-mediated disorders affecting the gastrointestinal (GI) tract. The current hypothesis for the pathogenesis of IBD involves a complex interplay between the mucosal immune system, environmental factors and the intestinal microbiota in a genetically susceptible 
host (1-4). The role that enteric bacteria play in the initiation, progression, and maintenance of the GI inflammatory process represents a particularly active area of investigation. Studies using rodent models as well as characterization of IBD patients, strongly implicate the gut microbiota as having a significant impact on the pathogenesis of colitis (5-8). For example, it has been observed that inflammatory bowel diseases correlate with dysbiosis (i.e., reduced diversity/complexity of the microbiota) (9-13). There is evidence of demonstrable changes in the abundance of specific bacterial taxa associated with IBD including an increase in Proteobacteria in humans, mice, and companion animals (1418). In addition, a decrease in Clostridium cluster groups IV and XIVa have been noted in patients with active $\operatorname{IBD}(9,13,19,20)$. These Clostridium cluster groups comprise a large proportion of the gut microbiota in healthy individuals and are known producers of short chain fatty acids, such as butyrate, which serve as an important energy source for colonocytes as well as regulatory molecules for regulatory T-cells $(21,22)$. Although it is well established that microbial-derived products activate both innate and adaptive immune cells and contribute to intestinal inflammation (23-26), a key question remains as to what extent the inflammation associated with IBD directly causes changes in the abundance of specific taxa.

To better understand the relationship between the host microbiota and immune system responses, we chose to use interleukin-10 deficient (IL-10 $0^{-/}$) mice to assess the development of GI inflammation and changes in the resident microbiota over time (i.e., 4 to 19 weeks of age) $(27,28)$. IL-10 is a key cytokine that facilitates immune regulation (29) and consequently IL-10 ${ }^{-/-}$mice develop spontaneous enterocolitis associated with the lack of regulatory $\mathrm{T}$ cells. The manifestation of disease can vary in severity depending on the composition of the intestinal microbiota and the genetic background of the mice $(27,30)$. The importance of mouse strain and the microbial composition to the development of colitis in IL- $10^{-/-}$mice was elegantly studied by Hart at al. In their study they transferred embryos into surrogate dams from various vendors and then examined the resulting offspring for inflammation (31). Compared to IL- $10^{-/-}$mice reared under conventional housing conditions, mice maintained under specific-pathogen free (SPF) conditions (i.e., absence of Helicobacter species) have attenuated disease while germ-free IL-10 $10^{-/}$animals fail to develop disease (32-34). A study by Whary et al. revealed that at least two bacterial species (Lactobacillus reuteri and Helicobacter hepaticus) needed to be present in the GI microbiota before inflammation could develop (35). Mice on a $\mathrm{C} 3 \mathrm{H} / \mathrm{HeJBir}$ background are highly susceptible to disease compared to other IL-10 ${ }^{-/-}$strains such as $\mathrm{C} 57 \mathrm{BL} / 6 \mathrm{~J}$ which are resistant to the development of colitis $(4,30)$. This is in part because the parental strain $(\mathrm{C} 3 \mathrm{H} / \mathrm{HeJBir})$ is prone to spontaneous colitis due to the presence of the major colitis susceptibility locus (Cdcs1) on chromosome $3(3,36,37)$.

While IL-10 $10^{-/-}$mouse models have been used to correlate differences in bacterial taxa present with the severity of inflammation (38-41), we reasoned that additional insights into the disease process can be gained from a longitudinal study that describe the dynamic changes in the microbiota over multiple time points as inflammation progresses $(11,42)$. To address this unknown, we used C3Bir.129P2(B6)-Il10 ${ }^{\operatorname{tm} 1 C g n} / \mathrm{Lt}$ (C3Bir IL-10 $0^{-/-}$) mice as a genetic model of gastrointestinal inflammation $(28,30,43-45)$.

The cecal microbiota of IL- $10^{-/-}$mice, along with that of $\mathrm{C} 3 \mathrm{H} /$ $\mathrm{HeJ}$ control animals, were characterized by $16 \mathrm{~S}$ rRNA gene amplicon sequencing along with histological observations and measurements of serological biomarkers of inflammation to assess changes in the microbial composition and concurrent host responses between 4 and 19 weeks of age. The histological and inflammatory biomarker data indicated that mucosal inflammation in C3Bir IL-10 $10^{-/-}$mice was moderate to severe as early as 4 weeks of age. Over the course of the 15-week study, an increase in the Shannon diversity index and the number of observed bacterial species was seen only in WT mice. Specific bacterial taxa were altered in abundance in the $\mathrm{IL}-10^{-/-}$mice, including a reduction in bacteria generally regarded as beneficial to the host such as members of the Clostridium cluster group XIVa, which is reduced in patients with $\operatorname{IBD}(13,46)$. An increase in Enterobacteriaceae was also observed, reaching 8\% of the total cecal bacterial community at 19 weeks, compared to less than $0.5 \%$ in WT mice. We also observed greater variability in the microbial composition throughout the study in the IL- $10^{-/-}$mice, which is consistent with recent observations in human IBD patients (11). We also used the metagenome prediction software, PICRUSt, to look at differences between the two communities (47). The results from our analysis revealed that the IL- $10^{-/-}$community had a greater number of predicted functions than the WT community post 4 weeks of age. These results build upon prior work evaluating the C3Bir $\mathrm{IL}_{-1} 10^{-/}$ mouse model and reveals a strong correlation between levels of inflammatory biomarkers (e.g., cytokines and chemokines) and the failure to develop a diverse and rich microbial community that otherwise occurs in wildtype mice $(4,38,39)$.

\section{MATERIALS AND METHODS}

\section{Animals}

Four-week-old female homozygous IL- $10^{-/-}$mice on a $\mathrm{C} 3 \mathrm{H} /$ $\mathrm{HeJBir}$ background (C3Bir.129P2(B6)-Il10 $0^{\text {tm1Cgn}} / \mathrm{Lt}$ ) and $\mathrm{C} 3 \mathrm{H} /$ $\mathrm{HeJ}$ controls were obtained from Jackson Laboratory (Bar Harbor, ME) in two separate shipments. The C3Bir IL-10 ${ }^{-1-}$ mice were positive for both $H$. hepaticus and Helicobacter muridarum. As the mice from different litters were mixed with the shipping container, they were then randomly placed into cages with a maximum of five mice per cage. At Iowa State University, animals were housed under SPF conditions in Innocage ${ }^{\circledR}$ IVC cages supported by an Innovive IVC rack (San Diego CA). All mice were maintained in the same room (12:12 h dark/light cycle) and there were no other mice housed within this room. Mice were allowed ad libitum access to 2019S diet from Envigo (Madison, WI) and the drinking water was acidified $(\mathrm{pH}$ 2.8-3.2). All provisions (food, water, bedding) were autoclaved prior to use. Body weights were measured three times per week 
during the experiment. The mice were all routinely monitored for appearance of any clinical signs of disease (e.g., weight loss, diarrhea, rectal bleeding). All animal procedures were performed in accordance with the experimental protocol approved by the Iowa State University Institutional Animal Care and Use Committee.

\section{Sample Collection and Preparation}

Randomly selected (i.e., from different cages) IL- $10^{-/-}$mice $(\mathrm{n}=5$ to 13 per time point) and the $\mathrm{C} 3 \mathrm{H} / \mathrm{HeJ}$ age-matched cohorts were necropsied at $4,7,10,12$, or 19 weeks of age. At each time point, mice were collected from a multiple of cages for each cohort to avoid assessing a cage effect. Blood was collected via cardiac puncture following euthanasia using $\mathrm{CO}_{2}$ asphyxiation. For DNA extraction, the cecum was aseptically excised and a portion of each cecum with contents were snap frozen in liquid nitrogen and stored at $-20^{\circ} \mathrm{C}$. The remaining cecal and colonic tissues from the same mice, devoid of contents, were placed in $10 \%$ buffered formalin for histopathologic evaluation.

\section{Macroscopic Assessment of Intestinal Lesions}

Macroscopic lesions of the cecum were scored using the following parameters: 1) atrophy, 2) enlarged cecal tonsil, 3) diarrheic luminal contents, 4) presence of fresh blood, 5) gross thickening (edema) of tissue. Lesion severity scores were based on the number of gross lesions with a maximum score of 5 , indicative of severe disease. Macroscopic lesions of the colon were similarly scored using the following parameters: 1) presence of fresh blood, 2) gross thickening (edema) of tissue, 3) diarrheic luminal contents. Lesion severity scores were based on the number of gross lesions with a maximum score of 3 , indicative of severe disease.

\section{Histopathological Assessment}

Fixed tissues were embedded in paraffin, sectioned and stained with hematoxylin and eosin ( $\mathrm{H} \& \mathrm{E})$ for light microscope evaluation. Stained tissue sections of cecum and colon were scored in a blinded fashion by a board-certified veterinary pathologist $(\mathrm{JMH})$, as previously described $(48,49)$. The final histological score represented the numerical sum of all five parameters with each parameter scored from $0-5 \quad(0=$ no lesion, 5= maximum severity) with a maximum cumulative score of 25. Histopathologic parameters evaluated included: 1) mucosal ulceration, 2) magnitude of lamina propria infiltration and character of inflammatory cells, 3) mucosal edema, 4) stromal collapse, 5) crypt hyperplasia.

\section{Serum Cytokine/Chemokine Quantification}

At necropsy, blood was collected by cardiac puncture and allowed to clot for $24 \mathrm{~h}$ at $4^{\circ} \mathrm{C}$. Serum was harvested following centrifugation of the blood for $10 \mathrm{~min}$ at $10,000 \mathrm{x} g$ and was then stored at $-20^{\circ} \mathrm{C}$ until analyzed. Measurements of cytokine and chemokine concentrations were performed using a murine multiplexed antibody array according to the manufacturer's instructions (Millipore, Billerica, MA). The mean fluorescent intensity (MFI) values were converted to analyte concentrations using known standards and commercial software (xPONET ${ }^{\circledR}$ ).

\section{Serum Amyloid A (SAA) Quantification}

The concentration of the acute phase protein, serum amyloid A (SAA), in the serum was measured using a commercial ELISA kit (Tridelta Development, Ireland) according to the manufacturer's instructions. After completion of the reaction, the absorbance was measured at $450 \mathrm{~nm}$ (Spectra Max 190, Molecular Devices). The concentration of SAA in the serum was calculated based on known concentrations of SAA standards, which were evaluated on the same plate as the samples. All reactions were performed in duplicate.

\section{DNA Extraction From Tissues and Contents}

Total genomic DNA was extracted from cecal tissues and their contents using a bead beating and column extraction method (50). Samples were subjected to homogenization using zirconia beads (1:3 ratio of $0.5 \mathrm{~mm}$ and $0.1 \mathrm{~mm}$ beads) with subsequent heating to $70^{\circ} \mathrm{C}$ for $15 \mathrm{~min}$. This step was repeated twice. The DNA was purified using a QIAamp column (Qiagen, Valencia CA) and concentrations quantified using a Nanodrop spectrophotometer (Thermo Scientific, Wilmington DE).

\section{S rRNA Gene Amplicon Sequencing}

Amplicon sequencing was performed by the Research and Testing Laboratory (Lubbock, TX) using 454 pyrosequencing technology as previously described with primers forward 28F: GAGTT TGATCNTGGCTCAG and reverse 519R: GTNTTACN GCGGCKGCTG (51). Raw sequence data were screened, trimmed, filtered, denoised, and chimera depleted with default settings using the QIIME pipeline version 1.5.0 (52) and UCHIME. FASTA formatted sequences were then clustered into operational taxonomic unit (OTU) clusters with $96.5 \%$ identity (3.5\% divergence) using USEARCH (53). For each cluster, the seed sequence was placed in a FASTA formatted sequence file. This file was then queried against a database of high-quality sequences derived from NCBI using a distributed.NET algorithm that utilizes BLASTN+. The BLASTn+ outputs were compiled using a.NET and $C \#$ analysis pipeline. The data reduction analysis was performed as previously described (51). Data are deposited in GenBank's short read with accession number SRP033709.

To account for unequal sequencing depth across samples, subsequent analysis was performed on a randomly selected subset of 1,900 sequences per sample. This number was chosen to avoid exclusion of samples with lower number of sequence reads from further analysis. Alpha diversity (i.e., rarefaction) and beta diversity measures were calculated and plotted using QIIME. Differences in microbial communities between animal groups and time points were investigated using the phylogeny-based unweighted Unifrac distance metric. To determine if any groups of samples contained significantly different bacterial communities, the analysis of similarities (ANOSIM) function in the statistical software package PRIMER 6 (PRIMER-E Ltd., Lutton, UK) was used on the unweighted UniFrac distance matrix (17). 


\section{PICRUSt Analysis}

The software PICRUSt (Phylogenetic Investigation of Communities by Reconstruction of Unobserved States) (47) available through the Galaxy workflow framework $(54,55)$, was used to make functional gene content predictions based on $16 \mathrm{~S}$ rRNA gene data present in the Greengenes database (47). Linear discriminant analysis effect size (LEfSe) (56) was used to determine difference in predicted genes and their specific KEGG orthologs at the various time-points between WT and IL- $10^{-/-}$mice.

\section{Statistical Analysis}

All values were expressed as mean \pm SEM. Serum cytokine/ chemokine data and SAA data were normalized by log transformation. A repeated measures analysis of variance (ANOVA) model was used for the previously mentioned data, with treatment group, time and their interaction as fixed effects. The 454 pyrosequencing data were analyzed using a generalized linear mixed model, with the same fixed effects structure. T-tests were used to assess the differences between WT and IL-10 ${ }^{-/-}$at each time point. To test each treatment temporally, an effect comparison of time by group was used. Tukey's t-test was used for multiple pairwise comparisons among time points. Nonparametric data were evaluated using a Wilcoxon Rank Sums test. PICRUSt was used to predict the functional capabilities of bacteria based on the 16S rRNA gene data set. LEfSe was utilized to evaluate differentially abundant bacterial taxa and predicted function between the animal groups. P-values $\leq 0.05$ were considered significant for all tests. SAS software (SAS Institute Inc., Cary NC, USA) was used for all statistical calculations.

\section{RESULTS}

\section{Taxonomic Profiling Showed Altered Taxonomic Diversity Microbial Diversity in IL-10 ${ }^{-/-}$Mice Compared to WT Mice}

To compare the composition of the GI microbiota between C3Bir IL-10 $0^{-/-}$and WT $\mathrm{C} 3 \mathrm{H} / \mathrm{HeJ}$ mice, $16 \mathrm{~S}$ rRNA gene amplicon sequencing was used to identify the predominant bacterial taxa from cecal contents collected temporally from separate mice between 4 and 19 weeks of age. As the mice aged over the 19 weeks, rarefaction analysis of the cecal microbiota revealed that the number of OTUs increased in the WT mice (Figure 1A), as well as did the Shannon diversity index (Figure 1B). In contrast, the beta-diversity of the microbiota did not change in the IL- $10^{-/-}$mice over the 19 weeks of the study.
WT

A

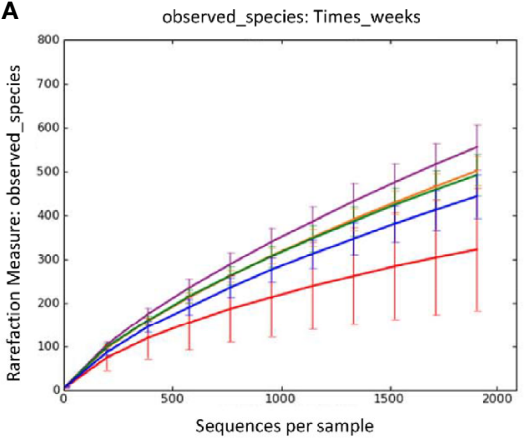

WT

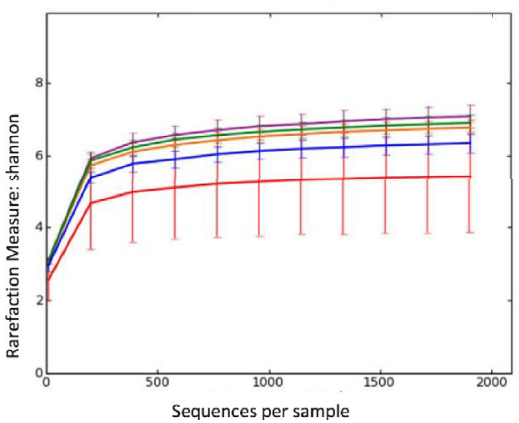

$\mathrm{IL}-10 \%$
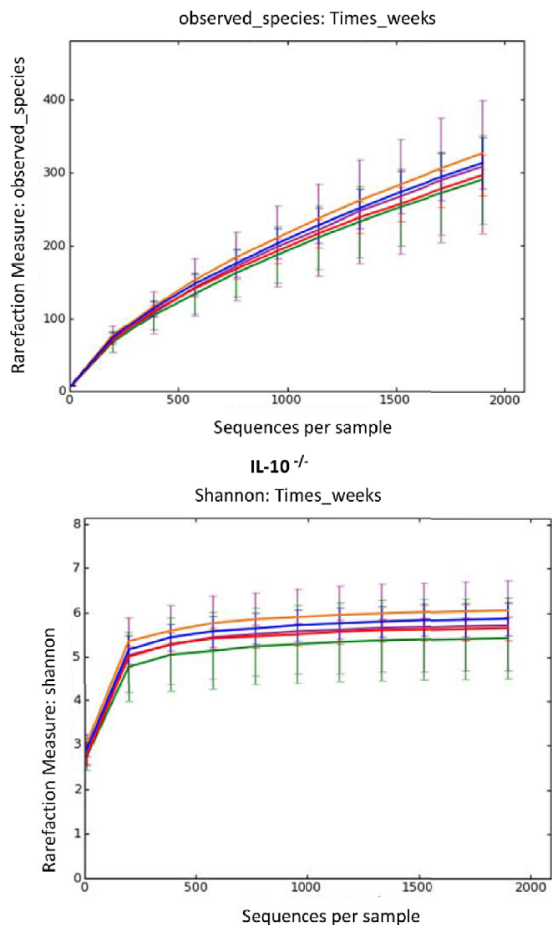

FIGURE 1 | Alpha diversity measurements of cecal microbial composition. (A) Rarefaction analysis index and (B) Shannon diversity index of 16S rRNA gene sequences obtained from cecal tissue and contents. Each line represents the average of each group from IL-10 $0^{-1-}$ and WT mice, as indicated. Data points are as follows: red, week 4; blue, week 7; orange, week 10; green, week 12; and purple, week 19, and error bars represent the standard deviations. The number of mice used for each strain at each time point varied as follows: at 4 weeks of age, $n=5 ;$ at 7 weeks of age, $n=10 ;$ at 10 weeks of age, $n=9$; at 12 weeks of age, $n=$ 13; at 19 weeks of age, $n=5$. 
Comparison of the taxonomic groups between IL-10 ${ }^{-/-}$and WT mice revealed differences in abundance of specific phyla. Members of the Firmicutes were the most abundant in both groups of mice, although the proportion was consistently higher in WT C3H/HeJ mice (approximately $90 \%$ of the microbial population) compared to the C3Bir $\mathrm{IL}-10^{-/-}$mice. Proteobacteria and Bacteroidetes were found at relatively high proportional levels in the IL-10 $10^{-1-}$ mice compared to WT mice throughout the study (Supplementary Figures 1A, B). Changes in abundance at the phylum level were minor over the 19 weeks of the study. In WT mice, Proteobacteria increased between weeks 4 and 7 ( $1 \%$ to $3 \%, \mathrm{p}=0.05)$ and then decreased between weeks 12 and 19 (3\% to 0.8\%, p=0.03) (Supplementary Figure 1B). At the phylum level, there were no significant changes in the microbial composition of the IL- $10^{-/-}$mice throughout the 19 weeks of the study.

To better understand the dynamics of the microbiota, the relative abundance of the most prevalent genera was tracked between weeks 4 and 19 (Supplementary Figure 2A). With the exception of Lactobacillus and Prevotella, the remaining taxa in the WT mice showed significant increases $(\mathrm{p} \leq 0.05)$ in abundance as the study progressed (Supplementary Figures 2B, C). By 19 weeks of age, members of the genus Eubacterium had expanded to represent $7.74 \%$ of the total population while the remaining genera remained collectively less than $10 \%$ of the total microbial community (Supplementary Figure 2C).

Consistent with the Shannon diversity index, there was no increase observed in the complexity of the cecal microbiota of the IL-10 $1{ }^{-/}$mice. In addition, multiple taxa (e.g., Blautia, Burkholderia, Butyrivibrio, Dorea, Lactococcus, Oscillibacter, Pseudomonas, and Roseburia) detected at 4 weeks of age decreased in relative abundance throughout the duration of the study (Supplementary Figures 2D, E). Of these genera, Lactococcus and Roseburia are generally considered beneficial to mucosal health. In contrast, there was a significant increase in Escherichia from 2\% to $8 \%$ of the total microbiota $(\mathrm{p}=0.004)$ between 12 and 19 weeks of age in the C3Bir IL- $10^{-/-}$mice. While the C3Bir IL- $10^{-/-}$mice were positive for $H$. hepaticus and $H$. muridarum, there was no evidence that there was an increase in Helicobacter species over the 19 weeks of the study.

\section{Functional Analysis of the Microbiomes of IL-10 ${ }^{-/-}$and WT Mice}

PICRUSt analysis was used to assess the extent to which differences in microbiota composition influenced predicted microbial functions over time. At week 4, the microbiota of the WT $\mathrm{C} 3 \mathrm{H} / \mathrm{HeJ}$ mice showed only a modest increase in the number of functional gene categories (GO categories) compared to the microbiota from the IL- $10^{-/-}$mice (Figure 2); however, there were fewer GO categories with LEfSe scores $>2$ for the WT mice (Supplementary Table 1). For the duration of the study, the major functional changes in the WT microbiota remained relatively constant with only a few functional categories with LEfSe scores > 2 (Supplementary Table 1A). With respect to the microbiota of the $\mathrm{C} 3 \mathrm{Bir} \mathrm{IL}-10^{-/-}$mice, an increase in the number of GO term categories was observed after week 7 weeks of age and these differences between WT and $\mathrm{KO}$

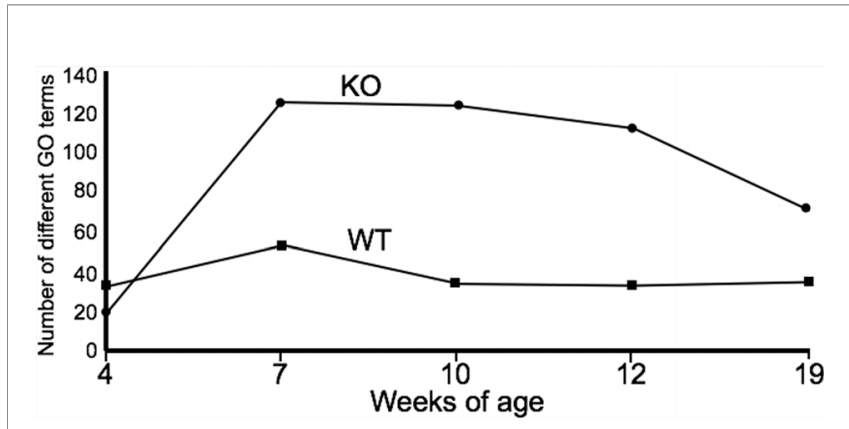

FIGURE 2 | Summary of PICRUSt analysis. The number of GO terms are shown at each point of the study for WT and IL-10 $1 /-$ mice, as indicated. The number of mice used for each strain at each time point varied as follows: at 4 weeks of age, $n=5$; at 7 weeks of age, $n=10$; at 10 weeks of age, $n=9$; at 12 weeks of age, $n=13$; at 19 weeks of age, $n=5$.

mice were largely maintained throughout the duration of the study (Figure 2). The functional categories whose representation showed marked changes in the IL- $10^{-/-}$mice, but not in WT mice, included metabolism, xenobiotic degradation, signal processing, biosynthesis of secondary metabolites, and DNA repair (Supplementary Table 1B). In the WT mice, the functional changes encompassed primarily carbohydrate and amino acid metabolism.

\section{Macroscopic/Microscopic Cecal Lesions Provide Evidence of Early Onset of Intestinal Inflammation}

To connect the observed differences in the microbiota between the IL- $10^{-/-}$and $\mathrm{C} 3 \mathrm{H} / \mathrm{HeJ}$ mice with changes in mucosal health, we compared differences in the expression of host inflammatory responses between the $\mathrm{C} 3 \mathrm{H} / \mathrm{HeJ}$ mice and the $\mathrm{C} 3 \mathrm{Bir} \mathrm{IL}-10^{-/}$ mice over the course of 19 weeks. While no significant differences were observed in macroscopic cecal lesions between the $\mathrm{C} 3 \mathrm{H} /$ $\mathrm{HeJ}$ and $\mathrm{IL}-10^{-/-}$mice at 4 weeks of age, the IL- $10^{-/-}$mice had significantly $(\mathrm{p} \leq 0.05)$ greater macroscopic lesion scores (range $0-5$ ) at all subsequent time points (Figure 3A). The observed typhlocolitis of the IL- $10^{-/-}$mice was characterized by the presence of intraluminal blood, tissue thickening, cecal atrophy, and enlarged lymphoid aggregates (Figure 3B). Similarly, the colons from the IL- $10^{-/-}$mice presented with higher macroscopic lesion scores (range $0-3$ ) at weeks 7,10 , and 12 compared to $\mathrm{C} 3 \mathrm{H} / \mathrm{HeJ}$ mice (Figure 3C) that were characterized by colonic tissue thickening and diarrheic luminal contents. Colon lengths of IL- $10^{-/-}$mice were found to be significantly ( $\mathrm{p} \leq 0.05)$ shorter at weeks 7 and 12 (Figure 3D). In contrast, colons from $\mathrm{C} 3 \mathrm{H} / \mathrm{HeJ}$ mice displayed no cecal or colonic macroscopic lesions at any point in the study.

Microscopic examination of both cecal and colonic tissues revealed statistically significant $(\mathrm{p} \leq 0.05)$ levels of inflammation present in the IL- $10^{-/-}$mice at all time points compared to the tissue from $\mathrm{C} 3 \mathrm{H} / \mathrm{HeJ}$ mice (Figures 4A, B). As shown in Figure 4C, cecal tissue sections from IL- $10^{-/-}$mice had noticeable mucosal hyperplasia, mononuclear cell infiltrates in the lamina 


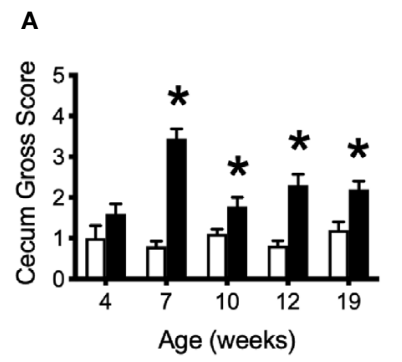

C

B

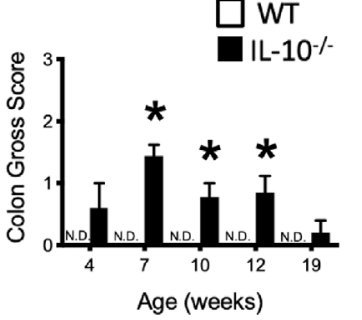

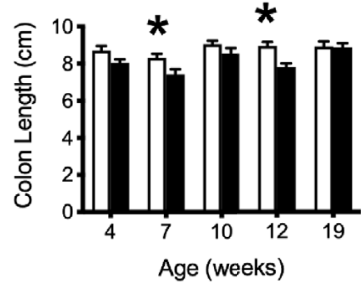

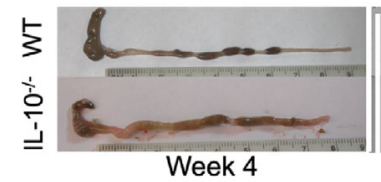

Week 4

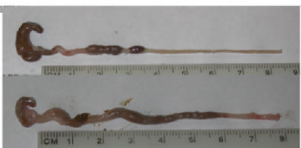

Week 7

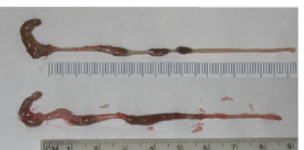

Week 10

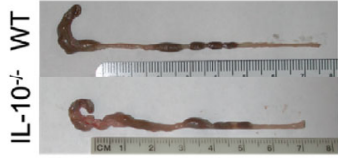

Week 12

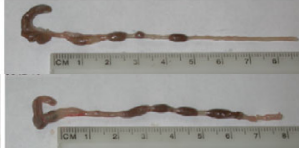

Week 19

FIGURE 3 | Macroscopic evaluation of Gl tissue from WT and IL-10 the cecum (A) and colon (C). Representative photomicrograph depicting colons from WT and IL-10 ${ }^{-/-}$mice at each time point as indicated (B). (D) Graphical comparison of colon lengths. Data are presented as mean \pm SEM. * $=p \leq 0.05$ comparing WT and IL-10 ${ }^{-/-}$for each time point. The number of mice used for each strain at each time point varied as follows: at 4 weeks of age, $n=5$; at 7 weeks of age, $n=10$; at 10 weeks of age, $n=9$; at 12 weeks of age, $n=13$; at 19 weeks of age, $n=5$.
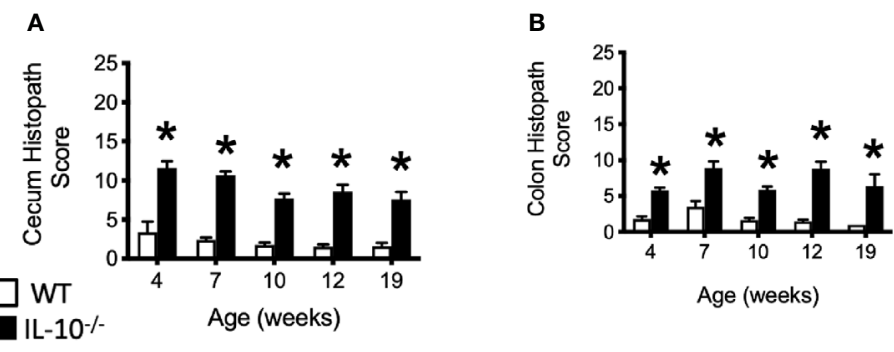

C

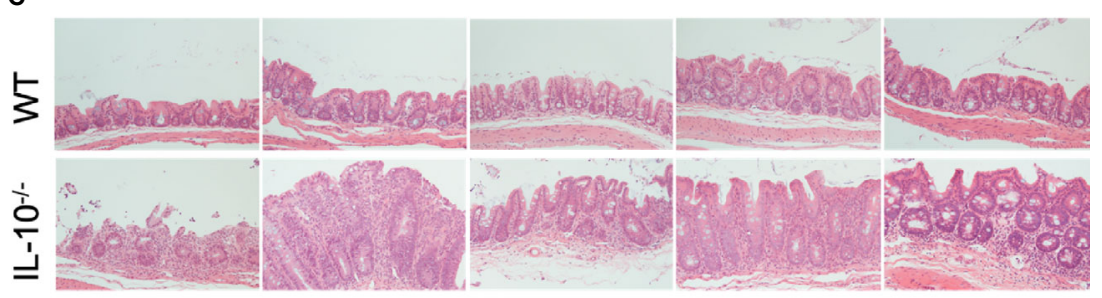

$\begin{array}{lllll}\text { Week } 4 & \text { Week } 7 & \text { Week } 10 & \text { Week } 12 & \text { Week } 19\end{array}$

FIGURE 4 | Microscopic evaluation of Gl tissue from WT and IL-10 ${ }^{-/-}$mice. Microscopic lesion scores for mice for the cecum (A) and colon (B). Data are presented as mean \pm standard error of the mean (SEM) and for statistical comparison, ${ }^{*}=\mathrm{p} \leq 0.05$ when comparing WT and IL-10 ${ }^{-/-}$mice at a given time point. See Materials and Methods for the criteria used to generate the lesion scores. (C) Representative photomicrographs of cecal tissue collected from WT and IL-10 ${ }^{-/}$mice at different time points. Tissue samples were fixed in 10\% buffered formalin and routinely processed prior to staining with hematoxylin and eosin. All images were magnified 200X. The number of mice used for each strain at each time point varied as follows: at 4 weeks of age, $n=5 ;$ at 7 weeks of age, $n=10$; at 10 weeks of age, $n=9$; at 12 weeks of age, $n=13$; at 19 weeks of age, $n=5$. 
propria, and a loss of goblet cells, that was not observed in the cecal tissue of $\mathrm{C} 3 \mathrm{H} / \mathrm{HeJ}$ mice.

\section{Serum Pro-Inflammatory/Chemotactic Cytokines and SAA Are Increased in IL- $10^{-/-}$Mice Versus WT Mice}

To investigate the progression of the systemic inflammatory response of $\mathrm{IL}-10^{-/-}$mice over time, concentrations of proinflammatory cytokines and chemokines were measured in serum samples as biomarkers of inflammation. At 4 weeks of age, there were already significant elevation of chemokines and cytokines (e.g., IP-10, IL-1 $\beta$, IL-2, IL-12(p70), RANTES, IL-13, MIP- $1 \alpha$, and GM-CSF) in the serum of the IL- $10^{-/-}$mice but these elevated levels did not persist over the course of the experiment (Figure 5). Over the course of the 19 weeks, significantly ( $\mathrm{p} \leq 0.05$ ) elevated concentrations of G-CSF, IL$1 \alpha$, IL-6, and TNF- $\alpha$ (Figures 6A-D) were observed in the serum of the IL- $10^{-/-}$mice in comparison to $\mathrm{C} 3 \mathrm{H} / \mathrm{HeJ}$ mice. IFN$\gamma$ levels were significantly $(\mathrm{p} \leq 0.05)$ elevated in $\mathrm{IL}-10^{-/-}$mice at each time point except week 19 (Figure 6E). As an acute phase protein observed during inflammation, SAA was significantly increased $(\mathrm{p} \leq 0.05)$ in the serum of $\mathrm{IL}-10^{-/-}$mice compared to $\mathrm{C} 3 \mathrm{H} / \mathrm{HeJ}$ mice at all-time points (Figure 6F). KC and IL-17 were the only two cytokines/chemokines that were elevated at week 4 (during the initial inflammatory surge) and then again at week 19
(Figures 7A, B) when severe weight became apparent in the $\mathrm{IL}-10^{-/-}$mice and the experiment was terminated (Figure 7C).

\section{DISCUSSION}

Throughout the experiment, the C3Bir IL- $10^{-/-}$mice presented with severe, histopathological typhlocolitis. This is consistent with previous studies using this $\operatorname{IL}-10^{-/-}$mouse model $(3,4)$. Unexpectedly, cecal inflammation was already present at 4 weeks of age and was associated with the increased expression of serum cytokines/chemokines (IP-10, IL-1 $\beta$, IL-2, IL-12(p70), RANTES, IL-13, MIP-1 $\alpha$, GM-CSF) in the IL- $10^{-/-}$mice. There were also a subset of cytokines/chemokines that were chronically elevated throughout the duration of the experiment: G-CSF, IL-1 $\alpha$, IL-6, TNF- $\alpha$, and IFN- $\gamma$. These observations in the presence of serum cytokines/chemokines emphasizes the dynamic nature of chronic inflammation and suggests that these different cytokines may contribute temporally to the initiation, maintenance, and/or attempts to resolve chronic inflammation in IL-10 $0^{-/-}$mice (57). KC and IL-17 interestingly were elevated at both the onset of disease ( 4 weeks) and when the mice developed clinical disease at 19 weeks of age; however, these cytokines were not significant elevated at other timepoints. The observed profile of cytokine production dovetail nicely with reports from others
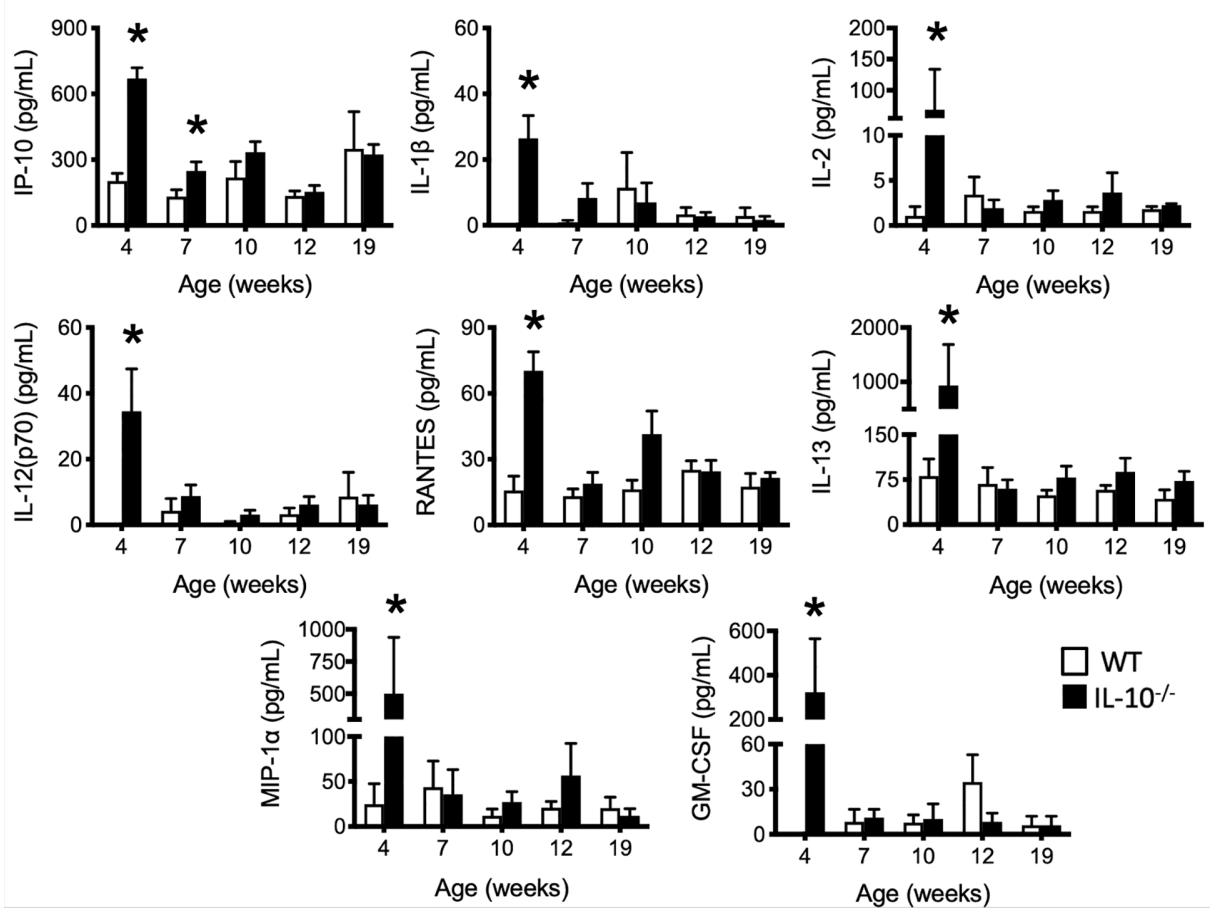

FIGURE 5 | Levels of selected serum cytokines and chemokines elevated at early time points in the serum of IL-10 ${ }^{-/-}$mice. Immune factors in serum samples collected between four and 19 weeks of age that were assayed included: IP-10, IL-1 $\beta$, IL-2, IL-12(p70), RANTES, IL-13, MIP-1 $\alpha$ and GM-CSF. Serum samples were collected from WT (white bars) and IL-10 ${ }^{-1-}$ (black bars) mice. Data are presented as mean \pm SEM. ${ }^{*}=\mathrm{p} \leq 0.05$ comparing samples between WT and IL-10 ${ }^{-/-}$mice at each time point. The number of mice used for each strain at each time point varied as follows: at 4 weeks of age, $n=5$; at 7 weeks of age, $n=10$; at 10 weeks of age, $n=9$; at 12 weeks of age, $n=13$; at 19 weeks of age, $n=5$. 

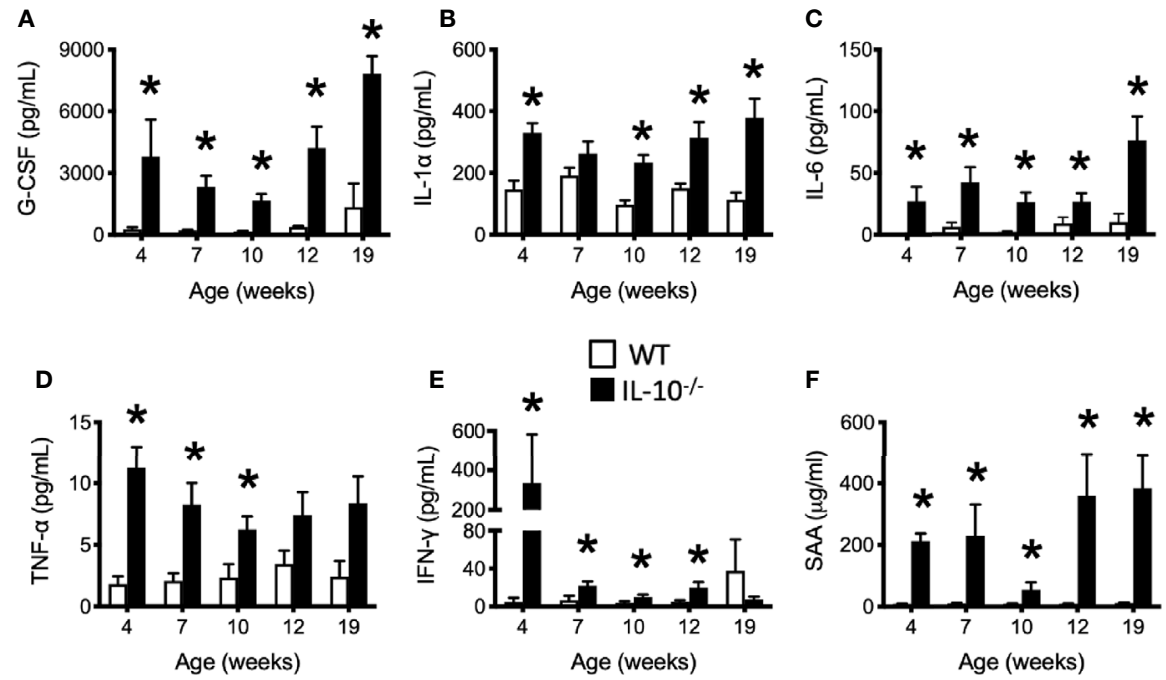

FIGURE 6 | Levels of serum cytokines and chemokines that were persistently elevated in the serum of IL-10/- mice. Immune factors assayed in serum samples collected between 4 and 19 weeks of age include: (A) G-CSF; (B) IL-1 $\alpha$; (C) IL-6; (D) TNF- $\alpha$ (E) IFN- $\gamma$; and (F) serum amyloid A (SAA). Serum samples were

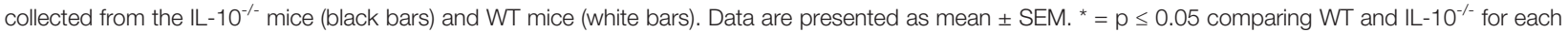
individual time point. The number of mice used for each strain at each time point varied as follows: at 4 weeks of age, $n=5$; at 7 weeks of age, $n=10$; at 10 weeks of age, $n=9$; at 12 weeks of age, $n=13$; at 19 weeks of age, $n=5$.

A

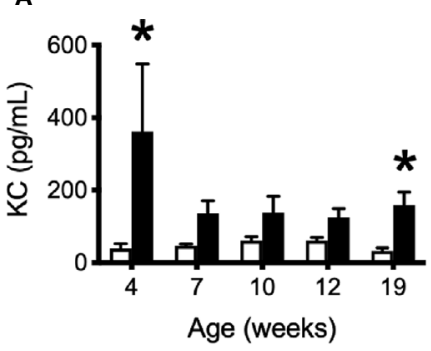

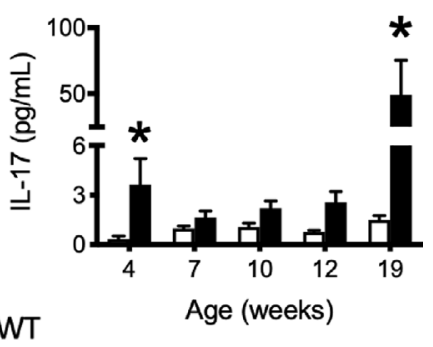

IL-10\%-

C

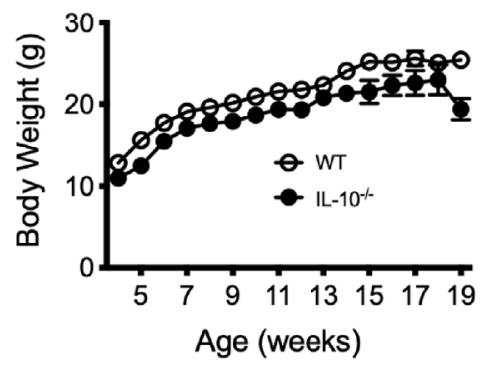

FIGURE 7 | Levels of cytokine and chemokines that were elevated in the serum of IL-10 ${ }^{-/-}$mice at 19 weeks of age. Concentrations of KC (A) and IL-17 (B) were measured in the serum of wild type (white bars) an IL-10-/- mice. Whole body weights of WT and IL-10 ${ }^{-/-}$mice during the 19 week trial (C). Data are presented as mean \pm SEM. Both groups of mice gained a similar amount of weight between weeks 4 and 18 of age $\left(\mathrm{IL}-10^{-/-}=12.0 \mathrm{~g}, \mathrm{WT}=\right.$ $12.2 \mathrm{~g}$ ). At each time point, there were equal numbers of WT and IL-10 ${ }^{-1-}$ mice included in the analysis. The number of mice used for each strain at each time point varied as follows: at 4 weeks of age, $n=5$; at 7 weeks of age, $n=10$; at 10 weeks of age, $n=9$; at 12 weeks of age, $n=13$; at 19 weeks of age, $\mathrm{n}=5$ 
regarding elevated cytokine levels in $\mathrm{IL}-10^{-/-}$mice. A study by Buchler et al. which also used $\mathrm{IL}-10^{-/-}$mice on a C3Bir background also showed increased levels of IL-6, IL-17, and IFN- $\gamma$ (4). Work by Matharu et al. also implicate the secretion of both IL-17 and IFN- $\gamma$ from dysregulated CD ${ }^{+}$regulatory T cells $\left(\mathrm{T}_{\mathrm{REG}}\right)$ in their model of IL-10 ${ }^{-1-}$ colitis where the mice were deficient in both IL-10 and TLR4 (58). These results demonstrate the importance of an effective $\mathrm{T}_{\mathrm{REG}}$ cell response in maintaining mucosal health and highlights the cytoprotective benefits of TLR signaling. IL-10 and IL-17 were also implicated in the disease process by Eun et al. In their study, using germfree mice inoculated with seven bacterial species from an IBD patient, they examined the degree of inflammation in B6 and $129 \mathrm{IL}-10^{-/-}$ mice at two separate time points (59). As previously mentioned, this study also revealed that the severity of inflammation was greater in the $129 \mathrm{IL}-10^{-/-}$mice which correlated with the induction of antigen-specific IFN $\gamma$ and IL-17 at six and 12 weeks post-colonization.

The severity of inflammation that develops in $\mathrm{IL}-10^{-/-}$mice is dependent on the composition of the intestinal resident microbiota (60). Using a model of Helicobacter-induced IL-10 $0^{-/-}$ mouse of colitis, Yang and colleagues demonstrated that mice housed within different facilities developed colitis with characteristically different levels of inflammation. Using a 129/ SvEv IL- $10^{-/-}$mouse model of colorectal cancer, there is evidence that the nature of intestinal inflammation elicits changes in the microbiota (61). Based on the analysis of beta-diversity in the microbiota, we demonstrated that the dysbiosis observed in the IL$10^{-/-}$mice was associated with a failure to establish a diverse microbiota as was observed in the $\mathrm{C} 3 \mathrm{H} / \mathrm{HeJ}$ mice. The microbiota of both $\mathrm{C} 3 \mathrm{H} / \mathrm{HeJ}$ and IL-10 $10^{-/-}$mice was of comparable complexity at four weeks of age, which may not have been expected given the results obtained at later time points. However, after four weeks of age, the microbiota of the $\mathrm{C} 3 \mathrm{H} / \mathrm{HeJ}$ mice increased in diversity to levels never attained by the IL- $10^{-/-}$mice. As the $\mathrm{C} 3 \mathrm{H} / \mathrm{HeJ}$ mice aged, bacteria generally recognized as beneficial, such Eubacterium, Lactococcus, and Ruminococcus, significantly ( $\mathrm{p} \leq$ 0.05 ) increased in abundance and in Shannon diversity. This was not observed in the IL- $10^{-/-}$mice and this lack of diversity and richness is similar to that observed by Maharshak and colleagues at four weeks following colonization of germfree $\mathrm{IL}_{10} 0^{-/-}$mice with a SPF microbiota $(39,42)$.

At four weeks of age, the presence of elevated levels of proinflammatory cytokines was observed in the serum of the IL-10 ${ }^{-/-}$ mice. These observations suggest that there is a critical time where inflammation appears to interfere with the natural development or diversification of the microbiota. To our knowledge, this has not been previously reported. Despite the general appearance of health between four and 17 weeks of age, the C3Bir IL- $10^{-/-}$mice maintained a dysbiotic profile of their microbiota throughout the study; in other words, the dysbiosis did not abruptly develop with the onset of marked weight loss at 19 weeks of age. Consequently, it is likely that the reduced abundance of key taxa contributed to the chronicity and severity of colitis. For example, taxonomic characterization of the microbiota revealed that the IL- $10^{-/-}$mice experienced a general decrease in abundance of bacteria regarded as beneficial (e.g., Blautia, Lactococcus, and Roseburia) while the abundance of Proteobacteria (e.g., E. coli) increased. Similar increases in Proteobacteria have been noted in other $\mathrm{IL}-10^{-1}$ studies as well $(39,42)$. While the C3Bir IL-10 $0^{-/-}$mice were colonized by $H$. hepaticus and $H$. muridarum, there was no demonstrable increase in Helicobacter species over the 19 weeks of this study.

The development of the composition of the microbiota over time was hugely distinct between inflamed vs non-inflamed gastrointestinal tracts. The rarefaction analysis of observed species and the Shannon diversity index revealed an ordered increase in microbial diversity as the $\mathrm{C} 3 \mathrm{H} / \mathrm{HeJ}$ mice aged. In contrast, the C3Bir IL- $10^{-/-}$mice showed only a limited increase in the diversity of the observed microbial species over time. The progression of microbial diversity may have been significantly restricted as a consequence of the elevated levels of proinflammatory cytokine/chemokines seen at four weeks of age. As mentioned above, similar results were obtained in the study by Maharshak et al. which colonized germfree WT and IL-10 ${ }^{-/}$ mice with a SPF microbiota (39). Using fecal pellets as their source material, they reported a decrease in both microbial richness and diversity over time in the IL- $10^{-/-}$mice. In their WT mice, they reported increased bacterial richness over time supporting the data in this paper. In contrast, when Redhu et al. compared the fecal microbiota in IL-10 receptor knockout mice, they observed no differences in microbial diversity between the WT and IL-10R ${ }^{-1-}$ mice over time (41).

Identification of specific taxa from $16 \mathrm{~S}$ rRNA gene sequences also revealed substantial differences in the richness of the microbial composition at the phylum and genus levels. Statistically significant $(\mathrm{p} \leq 0.05)$ decreases in several genera in the C3Bir IL-10 $0^{-/-}$mice were observed over the course of the study. At 4 weeks of age, Blautia, Butyrivibrio, Lactococcus, Roseburia, and Ruminococcus spp. comprised $46 \%$ of the microbial community in the C3Bir IL- $10^{-/-}$mice but, by 7 weeks of age, these species represented only $21 \%$ of the microbiota support the impact of chronic inflammation on the composition of the intestinal microbiota. Furthermore, these taxa include members of the Lachnospiraceae family that is part of the Clostridium coccoides cluster (cluster XIVa) group which have been shown to be beneficial to intestinal health $(7,62)$. Reduced microbial diversity has been well documented both in human and companion animal IBD patients $(20,42,63)$. For example, studies have shown that reduction of species belonging to the $C$. coccoides cluster is a common feature in the microbial communities colonizing the colon of human IBD patients $(7,62,64-67)$. In a study evaluating IBD in twins, Roseburia spp. were decreased in both the feces and ileal biopsy samples of patients with ileal CD compared to healthy controls (13).

In addition to reductions of specific members of the community, there are increases in certain microbes associated with IBD as well. In particular, increased abundance of Enterobacteriaceae has been linked to the pathogenesis of mucosal inflammation in diverse species including humans, 
rodents, dogs, and cats $(17,63,68-70)$. As has been noted in IBD patients, a significant increase in the abundance of Enterobacteriaceae was observed in the IL-10 $10^{-/-}$mice at 19 weeks of age and as the mice began to develop clinical signs of disease (i.e., weight loss) which was also accompanied by increased levels of IL-17 and $\mathrm{KC}$ in their serum. In these current studies, the C3Bir IL-10 ${ }^{-/-}$mice abruptly lost greater than $10 \%$ of their body weight and were removed from the study for humane reasons (Figure S3). IL-17 is increased in humans with IBD and has been associated with intestinal inflammation in several animal models $(42,71,72)$. Previous studies using the IL$10^{-/-}$model of colitis have either used denaturing gradient gel electrophoresis (DGGE) for their analysis of microbial compositional $(40,42)$ or have only collected fecal pellets for 4 weeks post-colonization of germ-free mice with a SPF microbiota or at 8 and 10 weeks of age (39). In contrast to the present work, these previous studies provide limited information regarding the dynamic changes of the microbial diversity or the inflammatory responses over time.

Using PICRUSt analysis, these results revealed functional differences in the microbiota between groups of mice that corresponded with the difference in environmental conditions encountered by the cecal microbial communities. $\mathrm{C} 3 \mathrm{H} / \mathrm{HeJ}$ mice exhibited fewer marked changes in functional categories over time compared to age matched IL- $10^{-/-}$mice suggesting that a more orderly maturation of the gut microbiota had occurred in the WT mice. Inspection of functional categories with LEfSe scores $>2$ revealed a number of gene functions in IL- $10^{-/-}$mice that were not significantly altered in $\mathrm{C} 3 \mathrm{H} / \mathrm{HeJ}$ mice including DNA recombination, replication and repair mechanisms (week 7), signal transduction, cell motility and chemotaxis (week 12), and biosynthesis of secondary metabolites and xenobiotics degradation and metabolism (week 19). These differences likely represent adaptations in the functions of the microbial community in the C3Bir IL- $10^{-/-}$mice in response to the chronic gastrointestinal inflammation and the use of metabolic biomarkers may represent useful biomarkers to better understand the role of inflammation in shaping the gut microbiota.

Based on the results of this study, we find that there is a window of opportunity for microbial progression that is crucial for the development of a diverse microbiome. Similar studies have shown this effect in infants given antibiotics (73). A Finnish study by Korpela et al. revealed that children prescribed macrolide antibiotics between 2-7 years of age had a reduction in microbial richness even 24 months after antibiotic exposure (74). A longitudinal study by Yassour et al. that utilized metagenomics found that children given antibiotics had less diverse and less stable microbial communities compared to untreated children (75). These studies support our conclusion that if the progression of the microbiota is hindered (through inflammation or antibiotic usage) the effects are long-term with regards to the stability and diversity of the microbiome.

In conclusion, this study tracked both inflammation and cecal microbial composition temporally in C3Bir IL- $10^{-/-}$mice over multiple time points using $16 \mathrm{~S}$ rRNA gene amplicon sequencing. Results indicate that the C3Bir IL- $10^{-/-}$mice had begun to develop intestinal inflammation as early as 4 weeks of age when their microbial diversity was at its greatest. The results obtained in this study suggests that intervention treatments, such as administration of prebiotics and/or probiotics, or anti-inflammatory therapies, may be more effective when administered at a critical time point to establish or maintain a beneficial microbiota contributing to improved gut health and clinical outcomes.

\section{DATA AVAILABILITY STATEMENT}

The raw data underlying the figures and tables associated with this manuscript have been made publically available. The short read sequences related to the analysis of the microbiota is deposited with NCBI under the BioProjects tab with an accession number of PRJNA231086. The ordinal data for the graphical data is deposited with Open Science Framework (doi:10.17605/OSF.IO/QT8GH).

\section{ETHICS STATEMENT}

Before any animal related work was performed, the animal studies were reviewed and approved by Institutional Animal Care and Use Committee, Iowa State University, Ames, Iowa, USA.

\section{FUNDING}

This work was supported in part by internal research grants provided by Iowa State University, College of Veterinary Medicine and Graduate College as well as funds provided by the National Institute of General Medicine (R01GM099537.

\section{AUTHOR CONTRIBUTIONS}

A-MO performed the animal studies, collected data, and generated the initial figures and first draft. AR-T, AJ, and GP were involved in experimental design, data interpretation, and manuscript editing. CW performed statistical analysis. JS analyzed genomic data, generated figures and $\mathrm{KO}$ term analyses. JH performed the blinded histopathological analyses and contributed to data interpretation and discussion. MW was supervisor in charge of project over-sight, data analysis, writing and editing, and financial support of the project along with AJ and GP. All authors contributed to the article and approved the submitted version.

\section{ACKNOWLEDGMENTS}

We would like to acknowledge the technical contributions of Mary Jane Long as well as the animal care staff at Iowa State University. 


\section{SUPPLEMENTARY MATERIAL}

The Supplementary Material for this article can be found online at: https://www.frontiersin.org/articles/10.3389/fimmu.2020. 585431/full\#supplementary-material

Supplementary Figure 1 | Taxonomic composition of the cecal microbiota at the phylum level. (A) Phylum level composition of WT and IL-10 $1 /$ mice, as indicated, throughout the study. (B) Specific phyla with statistically significant changes in abundance over the course of the study from WT and IL-10 $10^{-/-}$mice. The relative abundance (\%) for each group is shown and p-values are shown parenthetically. The number of mice used for each strain at each time point varied as follows: at 4 weeks of age, $n=5$; at 7 weeks of age, $n=10$; at 10 weeks of age, $n=9$; at 12 weeks of age, $n=13$; at 19 weeks of age, $n=5$.

Supplementary Figure 2 | Taxonomic composition of the cecal microbiota at the genus level. (A) Genus level composition of WT and IL-10 $1 /$ mice cecal microbiome

\section{REFERENCES}

1. Kostic AD, Xavier RJ, Gevers D. The microbiome in inflammatory bowel disease: current status and the future ahead. Gastroenterology (2014) 146 (6):1489-99. doi: 10.1053/j.gastro.2014.02.009

2. Sartor RB. Mechanisms of disease: pathogenesis of Crohn's disease and ulcerative colitis. Nat Clin Pract Gastroenterol Hepatol (2006) 3(7):390-407. doi: 10.1038/ncpgasthep0528

3. Bleich A, Buchler G, Beckwith J, Petell LM, Affourtit JP, King BL, et al. Cdcs1 a major colitis susceptibility locus in mice; subcongenic analysis reveals genetic complexity. Inflamm Bowel Dis (2010) 16(5):765-75. doi: 10.1002/ ibd.21146

4. Buchler G, Wos-Oxley ML, Smoczek A, Zschemisch NH, Neumann D, Pieper $\mathrm{DH}$, et al. Strain-specific colitis susceptibility in IL10-deficient mice depends on complex gut microbiota-host interactions. Inflamm Bowel Dis (2012) 18 (5):943-54. doi: 10.1002/ibd.21895

5. Abraham C, Medzhitov R. Interactions between the host innate immune system and microbes in inflammatory bowel disease. Gastroenterology (2011) 140:1729-37. doi: 10.1053/j.gastro.2011.02.012

6. Gkouskou KK, Deligianni C, Tsantsanis C, Eliopoulos AG. The gut microbiota in mouse models of inflammatory bowel disease. Front Cell Infect Microbiol (2014) 4:28. doi: 10.3389/fcimb.2014.00028

7. Hold GL, Smith M, Grange C, Watt ER, El-Omar EM, Mukhopadhya I. Role of the gut microbiota in inflammatory bowel disease pathogenesis: what have we learned in the past 10 years? World J Gastroenterol (2014) 20:1192-210. doi: $10.3748 /$ wjg.v20.i5.1192

8. Strober W. Impact of the gut microbiome on mucosal inflammation. Trends Immunol (2013) 34:423-30. doi: 10.1016/j.it.2013.07.001

9. Frank DN, St. Amand AL, Feldman RA, Boedeker EC, Harpaz N, Pace NR. Molecular-phylogenetic characterization of microbial community imbalances in human inflammatory bowel diseases. Proc Natl Acad Sci USA (2007) 104:13780-5. doi: 10.1073/pnas.0706625104

10. Gevers D, Kugathasan S, Denson LA, Vazquez-Baeza Y, Van Treuren W, Ren B, et al. The treatment-naive microbiome in new-onset Crohn's disease. Cell Host Microbe (2014) 15:382-92. doi: 10.1016/j.chom.2014.02.005

11. Halfvarson J, Brislawn CJ, Lamendella R, Vazquez-Baeza Y, Walters WA, Bramer LM, et al. Dynamics of the human gut microbiome in inflammatory bowel disease. Nat Microbiol (2017) 13:17004. doi: 10.1038/ nmicrobiol.2017.4

12. Matsuoka K, Kanai T. The gut microbiota and inflammatory bowel disease. Semin Immunopathol (2015) 37:47-55. doi: 10.1007/s00281-0140454-4

13. Willing BP, Dicksved J, Halfvarson J, Andersson AF, Lucio M, Zheng Z, et al. A pyrosequencing study in twins shows that gastrointestinal microbial profiles vary with inflammatory bowel disease phenotypes. Gastroenterology (2010) 139:1844-54.e1841. doi: 10.1053/j.gastro.2010.08.049

14. Chen L, Wang W, Zhou R, Ng SC, Li J, Huang M, et al. Characteristics of fecal and mucosa-associated microbiota in Chinese patients with inflammatory throughout the study. (B and $\mathbf{D})$. The \% abundance of specific bacterial genera from $\mathrm{WT}$ and $\mathrm{L}-10^{-1-}$ mice are shown by the colored lines and identified by the key. (C and E). Tables list specific genera with statistically significant changes in abundance over the course of the study from WT and IL-10 $10^{-1-}$ mice. The relative abundance (\%) for each group is shown and p-values are shown parenthetically. The number of mice used for each strain at each time point varied as follows: at 4 weeks of age, $n=5$; at 7 weeks of age, $n=10$; at 10 weeks of age, $n=9$; at 12 weeks of age, $n=13$; at 19 weeks of age, $n=5$.

Supplementary Table 1 | (A) LefSE scores for differentially abundant gene families from PICRUSt analysis. Functional categories and LefSE scores for WTmice. The number of mice used for each strain at each time point varied as follows: at 4 weeks of age, $n=5$; at 7 weeks of age, $n=10$; at 10 weeks of age, $n=9$; at 12 weeks of age, $n=13$; at 19 weeks of age, $n=5$. (B) LefSE scores for differentially abundant gene families from PICRUSt analysis. Functional categories and LefSE scores for $\mathrm{IL}-10^{-/}$mice. The number of mice used for each strain at each time point varied as follows: at 4 weeks of age, $n=5$; at 7 weeks of age, $n=10$; at 10 weeks of age, $n=9$; at 12 weeks of age, $n=13$; at 19 weeks of age, $n=5$.

bowel disease. Medicine (Baltimore) (2014) 93:e51. doi: 10.1097/ MD.0000000000000051

15. Frank DN, Robertson CE, Hamm CM, Kpadeh Z, Zhang T, Chen H, et al. Disease phenotype and genotype are associated with shifts in intestinalassociated microbiota in inflammatory bowel diseases. Inflamm Bowel Dis (2011) 17:179-84. doi: 10.1002/ibd.21339

16. Simpson KW, Dogan B, Rishniw M, Goldstein RE, Klaessig S, McDonough PL, et al. Adherent and invasive Escherichia coli is associated with granulomatous colitis in boxer dogs. Infect Immun (2006) 74:4778-92. doi: 10.1128/IAI.00067-06

17. Suchodolski JS, Dowd SE, Wilke V, Steiner JM, Jergns AE. 16S rRNA gene pyrosequencing reveals bacterial dysbiosis in the duodenum of dogs with idiopathic inflammatory bowel disease. PLoS One (2012) 7:e39333. doi: 10.1371/journal.pone.0039333

18. Thorkildsen LT, Nwosu FC, Avershina E, Ricanek P, Perminow G, Brackmann S, et al. Dominant fecal microbiota in newly diagnosed untreated inflammatory bowel disease patients. Gastroenterol Res Pract (2013) 2013:636785. doi: 10.1155/2013/636785

19. Sokol H, Seksik P, Furet JP, Firmesse G, Nion-Larmurier I, Beaugerie L, et al. Low counts of Faecalibacterium prausnitzii in colitis microbiota. Inflamm Bowel Dis (2009) 15:1183-9. doi: 10.1002/ibd.20903

20. Honneffer JB, Minamoto Y, Suchodolski JS. Microbiota alterations in acute and chronic gastrointestinal inflammation of cats and dogs. World J Gastroenterol (2014) 20(44):16489-97. doi: 10.3748/wjg.v20.i 44.16489

21. Leonel AJ, Alvarez-Leite JI. Butyrate: implications for intestinal function. Curr Opin Clin Nutr Metab Care (2012) 15:474-9. doi: 10.1097/MCO. 0b013e32835665fa

22. Macfarlane GT, Macfarlane S. Bacteria, colonic fermentation, and gastrointestinal health. J AOAC Int (2012) 95:50-60. doi: 10.5740/ jaoacint.SGE_Macfarlane

23. Grisham MB. Protective and pro-inflammatory roles of intestinal bacteria. Pathophysiology (2016) 23:67-80. doi: 10.1016/j.pathophys.2016.02.002

24. Ng SC, Bernstein CN, Vatn MH, Lakatos PL, Laftus EVJr, Tysk C, et al. Geographical variability and environmental risk factors in inflammatory bowel disease. Gut (2013) 62:630-49. doi: 10.1136/gutjnl-2012-303661

25. Sartor RB. Microbial influences in inflammatory bowel diseases. Gastroenterology (2008) 134:577-94. doi: 10.1053/j.gastro.2007.11.059

26. Geremia A, Biancheri P, Allan P, Corazza GR, Di Sabatino A. Innate and adaptive immunity in inflammatory bowel disease. Autoimmun Rev (2013) 13:3-10. doi: 10.1016/j.autrev.2013.06.004

27. Keubler LM, Beuttner M, Hager C, Bleich A. A multihit model: Colitis lessons from the Interleukin-10-deficient mouse. Inflamm Bowel Dis (2015) 21:196775. doi: 10.1097/MIB.0000000000000468

28. Rennick DM, Fort MM. Lessons from genetically engineered animal models. XII. IL-10-deficient (IL-10 $0^{-1-}$ ) mice and intestinal inflammation. Am J Physiol Gastrointest Liver Physiol (2000) 278:G829-833. doi: 10.1152/ ajpgi.2000.278.6.G829 
29. Asseman C, Mauze S, Leach MW, Coffman RL, Powrie F. An essential role for interleukin 10 in the function of regulatory $\mathrm{T}$ cells that inhibit intestinal inflammation. J Exp Med (1999) 190:995-1004. doi: 10.1084/jem.190.7.995

30. Mahler M, Leiter EH. Genetic and environmental context determines the course of colitis developing in IL-10-deficient mice. Inflamm Bowel Dis (2002) 8(5):347-55. doi: 10.1097/00054725-200209000-00006

31. Hart ML, Ericsson AC, Franklin CL. Differing complex microbiota alter disease severity of the IL- $10^{-/-}$mouse model of inflammatory bowel disease. Front Microbiol (2017) 8:792. doi: 10.3389/fmicb.2017.00792

32. Kuhn R, Lohler J, Rennick D, Rajewsky K, Muller W. Interleukin-10-deficient mice develop chronic enterocolitisse. Cell (1993) 75:263-74. doi: 10.1016/ 0092-8674(93)80068-P

33. Madsen KL, Malfair D, Gray D, Doyle JS, Jewell LD, Fedorak RN. Interleukin10 gene-deficient mice develop a primary intestinal permeability defect in response to enteric microflora. Inflamm Bowel Dis (1999) 5:262-70. doi: 10.1097/00054725-199911000-00004

34. Sellon RK, Tonkonogy S, Schultz M, Dieleman LA, Grenther W, Balish E, et al. Resident enteric bacteria are necessary for development of spontaneous colitis and immune system activation in interleukin-10deficient mice. Infect Immun (1998) 66:5224-31. doi: 10.1128/ IAI.66.11.5224-5231.1998

35. Whary MT, Taylor NS, Feng Y, Ge Z, Muthupalani S, Versalovic J, et al. Lactobacillus reuteri promotes Helicobacter hepaticus-associated typhlocolitis in gnotobiotic B6.129P2-IL-10 ${ }^{\mathrm{tm} 1 \mathrm{Cgn}}\left(\mathrm{IL}-10^{-/-}\right)$mice. Immunology (2011) 133 (2):165-78. doi: 10.1111/j.1365-2567.2011.03423.x

36. Buettner M, Bleich A. Mapping colitis susceptibility in mouse models: distal chromosome 3 contains major loci related to Cdcs1. Physiol Genomics (2013) 45(20):925-30. doi: 10.1152/physiolgenomics.00084.2013

37. Beckwith J, Cong Y, Sundberg JP, Elson CO, Leiter EH. Cdcs1, a major colitogenic locus in mice, regulates innate and adaptive immune response to enteric bacterial antigens. Gastroenterology (2005) 129(5):1473-84. doi: 10.1053/j.gastro.2005.07.057

38. Bibiloni R, Simon MA, Albright C, Sartor B, Tannock GW. Analysis of the large bowel microbiota of colitic mice using PCR/DGGE. Lett Appl Microbiol (2005) 41:45-51. doi: 10.1111/j.1472-765X.2005.01720.x

39. Maharshak N, Packey CD, Ellermann M, Manick S, Siddle JP, Huh EY, et al. Altered enteric microbiota ecology in interleukin 10-deficient mice during development and progression of intestinal inflammation. Gut Microbes (2013) 4(4):316-24. doi: 10.4161/gmic.25486

40. Knoch B, Nones K, Barnett MP, McNabb WC, Roy NC. Diversity of caecal bacteria is altered in interleukin-10 gene-deficient mice before and after colitis onset and when fed polyunsaturated fatty acids. Microbiology (2010) 156(Pt 11):3306-16. doi: 10.1099/mic.0.041723-0

41. Redhu NS, Bakthavatchalu V, Conaway EA, Shouval DS, Tsou A, Goettel JA, et al. Macrophage dysfunction initiates colitis during weaning of infant mice lacking the interleukin-10 receptor. Elife (2017) 6:e27652. doi: 10.7554/ eLife. 27652

42. Wohlgemuth S, Haller D, Blaut M, Loh G. Reduced microbial diversity and high numbers of one single Escherichia coli strain in the intestine of colitic mice. Environ Microbiol (2009) 11(6):1562-71. doi: 10.1111/j.14622920.2009.01883.x

43. Berg DJ, Davidson N, Kuhn R, Muller W, Menon S, Holland G, et al. Enterocolitis and colon cancer in interleukin-10-deficient mice are associated with aberrant cytokine production and CD4(+) TH1-like responses. J Clin Invest (1996) 98:1010-20. doi: 10.1172/JCI118861

44. Bristol IJ, Farmer MA, Cong Y, Zheng XX, Strom TB, Elson CO, et al. Heritable susceptibility for colitis in mice induced by IL-10 deficiency. Inflamm Bowel Dis (2000) 6:290-302. doi: 10.1097/00054725-200011000-00006

45. Farmer MA, Sundberg JP, Bristol IJ, Churchill GA, Li R, Elson CO, et al. A major quantitative trait locus on chromosome 3 controls colitis severity in IL10-deficient mice. Proc Natl Acad Sci USA (2001) 98:13820-5. doi: 10.1073/ pnas. 241258698

46. Mondot S, Kang S, Furet JP, Aguirre de Carcer D, McSweeney C, Morrison $\mathrm{M}$, et al. Highlighting new phylogenetic specificities of Crohn's disease microbiota. Inflamm Bowel Dis (2011) 17:185-92. doi: $10.1002 /$ ibd.21436

47. Langille MG, Zaneveld J, Caporaso JG, McDonald D, Knights D, Reyes JA, et al. Predictive functional profiling of microbial communities using $16 \mathrm{~S}$
rRNA marker gene sequences. Nat Biotechnol (2013) 31(9):814-21. doi: $10.1038 /$ nbt.2676

48. Jergens AE, Dorn A, Wilson J, Dingbaum K, Henderson A, Liu Z, et al. Induction of differential immune reactivity to members of the flora of gnotobiotic mice following colonization with Helicobacter bilis or Brachyspira hyodysenteriae. Microbes Infect (2006) 8:1602-10. doi: 10.1016/ j.micinf.2006.01.019

49. Jergens AE, Wilson-Welder JH, Dorn A, Henderson, Liu Z, Evans RB, et al. Helicobacter bilis triggers persistent immune reactivity to antigens derived from the commensal bacteria in gnotobiotic C3H/HeN mice. Gut (2007) 56:934-40. doi: 10.1136/gut.2006.099242

50. Yu Z, Morrison M. Improved extraction of PCR-quality community DNA from digesta and fecal samples. BioTechniques (2004) 36:808-12. doi: 10.2144/ 04365ST04

51. Dowd SE, Callaway TR, Wolcott RD, Sun Y, mcKeehan T, Hagevoort RG, et al. Evaluation of the bacterial diversity in the feces of cattle using $16 \mathrm{~S}$ rDNA bacterial tag-encoded FLX amplicon pyrosequencing (bTEFAP). BMC Microbiol (2008) 8:125. doi: 10.1186/1471-2180-8-125

52. Caporaso JG, Kuczynski J, Stombaugh J, Bittinger K, Busman FD, Costello EK, et al. QIIME allows analysis of high-throughput community sequencing data. Nat Methods (2010) 7:335-6. doi: 10.1038/nmeth.f.303

53. Edgar RC. Search and clustering orders of magnitude faster than BLAST. Bioinformatics (2010) 26:2460-1. doi: 10.1093/bioinformatics/btq461

54. Blankenberg D, Von Kuster G, Coraor N, Ananda G, Lazarus R, Mangan M, et al. Galaxy: a web-based genome analysis tool for experimentalists. Curr Protoc Mol Biol (2010) 89:19.10.1-19.10.21. doi: 10.1002/0471142727.mb1910s89

55. Goecks J, Nekrutenko A, Taylor J, Galaxy T. Galaxy: a comprehensive approach for supporting accessible, reproducible, and transparent computational research in the life sciences. Genome Biol (2010) 11:R86. doi: 10.1186/gb-2010-11-8-r86

56. Segata N, Izard J, Waldron L, Gevers D, Miropolsky L, Garrett WS, et al. Metagenomic biomarker discovery and explanation. Genome Biol (2011) 12: R60. doi: 10.1186/gb-2011-12-6-r60

57. Montufar-Solis D, Schaefer J, Hicks MJ, Klein JR. Massive but selective cytokine dysregulation in the colon of IL- $10^{-/-}$mice revealed by multiplex analysis. Int Immunol (2008) 20:141-54. doi: 10.1093/intimm/dxm126

58. Matharu KS, Mizoguchi E, Cotoner CA, Nguyen DD, Mingle B, Iweala OII, et al. Toll-like receptor 4-mediated regulation of spontaneous Helicobacterdependent colitis in IL-10-deficient mice. Gastroenterology (2009) 137 (4):1380-90 e1-3. doi: 10.1053/j.gastro.2009.07.004

59. Eun CS, Mishima Y, Wohigemuth S, Liu B, Bower M, Carroll IM, et al. Induction of bacterial antigen-specific colitis by a simplified human microbiota consortium in gnotobiotic interleukin- $10^{-/-}$mice. Infect Immun (2014) 82(6):2239-46. doi: 10.1128/IAI.01513-13

60. Yang I, Eibach D, Kops F, Brenneke B, Woltemate S, Schultze J, et al. Intestinal microbiota composition of interleukin-10 deficient C57BL/6J mice and susceptibility to Helicobacter hepaticus-induced colitis. PLoS One (2013) 8 (8):e70783. doi: 10.1371/journal.pone.0070783

61. Arthur JC, Peres-Chanona E, Muhlbauer M, Tomkovich S, Uronis JM, Fan BJ, et al. Intestinal inflammation targets cancer-inducing activity of the microbiota. Science (2012) 5:120-3. doi: 10.1126/science.1224820

62. Barcenilla A, Pryde SE, Martin JC, Duncan SH, Stewart CS, Henderson C, et al. Phylogenetic relationships of butyrate-producing bacteria from the human gut. Appl Environ Microbiol (2000) 66:1654-61. doi: 10.1128/ AEM.66.4.1654-1661.2000

63. Walker AW, Sanderson JD, Churcher C, Parker GC, Hudspith BN, Rayment $\mathrm{N}$, et al. High-throughput clone library analysis of the mucosa-associated microbiota reveals dysbiosis and differences between inflamed and noninflamed regions of the intestine in inflammatory bowel disease. BMC Microbiol (2011) 11:7. doi: 10.1186/1471-2180-11-7

64. Duncan SH, Hold GL, Harmsen HJ, Stewart CS, Flint HJ. Growth requirements and fermentation products of Fusobacterium prausnitzii, and a proposal to reclassify it as Faecalibacterium prausnitzii gen. nov., comb. nov. Int J Syst Evol Microbiol (2002) 52(Pt. 6):2141-6. doi: 10.1099/00207713-526-2141

65. Kabeerdoss J, JayakanthN P, Pugazhendhi S, Ramakrishna BS. Alterations of mucosal microbiota in the colon of patients with inflammatory bowel disease revealed by real time polymerase chain reaction amplification of $16 \mathrm{~S}$ 
ribosomal ribonucleic acid. Indian J Med Res (2015) 142:23-32. doi: 10.4103/ 0971-5916.162091

66. Sokol H, Pigneur B, Watterlot L, Lakhdari O, Bermudez-Humaran LG, Gratadoux JJ, et al. Faecalibacterium prausnitzii is an anti-inflammatory commensal bacterium identified by gut microbiota analysis of Crohn disease patients. Proc Natl Acad Sci U S A (2008) 105:16731-6. doi: 10.1073/pnas.0804812105

67. Vermeiren J, Van den Abbeele P, Laukens D, Digsnaes LK, De Vos M, Boon N, et al. Decreased colonization of fecal Clostridium coccoides/Eubacterium rectale species from ulcerative colitis patients in an in vitro dynamic gut model with mucin environment. FEMS Microbiol Ecol (2012) 79:685-96. doi: 10.1111/j.1574-6941.2011.01252.x

68. Janeczko S, Atwater D, Bogel E, Greiter-Wilke A, Gerold A, Baumgart M, et al. The relationship of mucosal bacteria to duodenal histopathology, cytokine mRNA, and clinical disease activity in cats with inflammatory bowel disease. Vet Microbiol (2008) 128:178-93. doi: 10.1016/j.vetmic. 2007.10.014

69. Seksik P, Rogottier-Gois L, Gramet G, Sultren M, Pochart P, Marteau P, et al. Alterations of the dominant faecal bacterial groups in patients with Crohn's disease of the colon. Gut (2003) 52:237-42. doi: 10.1136/gut.52.2.237

70. Suchodolski JS, Xenoulis PG, Paddock CG, Steiner JM, Jergens AE. Molecular analysis of the bacterial microbiota in duodenal biopsies from dogs with idiopathic inflammatory bowel disease. Vet Microbiol (2010) 142:394-400. doi: 10.1016/j.vetmic.2009.11.002

71. Fujino S, Andoh A, Bamba S, Ogawa A, Hata K, Araki Y, et al. Increased expression of interleukin 17 in inflammatory bowel disease. Gut (2003) 52:6570. doi: $10.1136 /$ gut.52.1.65
72. Seiderer J, Elben I, Diegelmann J, Glas J, Stallhofer J, Tillack C, et al. Role of the novel Th17 cytokine $I L-17 F$ in inflammatory bowel disease (IBD): upregulated colonic $I L-17 F$ expression in active Crohn's disease and analysis of the IL17F p.His161Arg polymorphism in IBD. Inflamm Bowel Dis (2008) 14:437-45. doi: 10.1002/ibd.20339

73. Neuman H, Forsythe P, Uzan A, Avni O, Koren O. Antibiotics in early life: dysbiosis and the damage done. FEMS Microbiol Rev (2018) 42(4):489-99. doi: 10.1093/femsre/fuy018

74. Korpela K, Salonen A, Virta LJ, Kekkonen RA, Forslund K, Bork P, et al. Intestinal microbiome is related to lifetime antibiotic use in Finnish preschool children. Nat Commun (2016) 7:10410. doi: 10.1038/ncomms10410

75. Yassour M, Vatanen T, Siljander H, Hamalainen AM, Harkonen T, Ryhanen SJ, et al. Natural history of the infant gut microbiome and impact of antibiotic treatment on bacterial strain diversity and stability. Sci Transl Med (2016) 8 (343):343ra81. doi: 10.1126/scitranslmed.aad0917

Conflict of Interest: The authors declare that the research was conducted in the absence of any commercial or financial relationships that could be construed as a potential conflict of interest.

Copyright (๑) 2021 Overstreet, Ramer-Tait, Suchodolski, Hostetter, Wang, Jergens, Phillips and Wannemuehler. This is an open-access article distributed under the terms of the Creative Commons Attribution License (CC BY). The use, distribution or reproduction in other forums is permitted, provided the original author(s) and the copyright owner(s) are credited and that the original publication in this journal is cited, in accordance with accepted academic practice. No use, distribution or reproduction is permitted which does not comply with these terms. 